\title{
Concubinato: resistência feminina, afetividades, famílias e mestiçagens na comarca de Sabará no século XVIII
}

\author{
Concubinage: Feminine Resistance, Affectivities, Families and Miscegenation in the \\ $18^{\text {th }}$ Century Sabará County
}

Igor Bruno Cavalcante dos Santos ${ }^{1}$

\begin{abstract}
Resumo
Este artigo objetiva analisar o concubinato na comarca de Sabará no século XVIII, mais especificamente na primeira metade dessa centúria, e o faz considerando o seu aspecto de consequência da vontade e escolha dos sujeitos envolvidos e não no espectro de relações marginais. Dentro de uma abordagem sociocultural, o estudo compreende a prática da mancebia enquanto resultado e resultante do intenso e complexo processo das mestiçagens processadas na América portuguesa. Como fonte, as devassas eclesiásticas e os testamentos foram privilegiados e ajudaram no sentido de pensarmos uma parte das intrincadas tramas do cotidiano que resultaram em arranjos familiares não legitimados perante as autoridades da época, porém, socialmente aceitos e reproduzidos dentro do cotidiano.
\end{abstract}

Palavras-chave: Concubinato; Afetividades; Escravidão; Família; Mestiçagens.

\begin{abstract}
This article aims to analyze concubinage in the 18th century Sabará district, more specifically in the first half of this century, and does so considering its aspect as a consequence of the will and choice of the subjects involved and not in the spectrum of marginal relations. Within a sociocultural approach, the study comprises the practice of 'mancebia' as a result and resulting of the intense and complex process of 'mestizaje' ocurred in Portuguese America. As a source, ecclesiastical inquery and wills were privileged and helped to think of some intricate plots of daily life that resulted in not legitimized family arrangements before the authorities of the time, but socially accepted and reproduced within everyday life.
\end{abstract}

Keywords: Concubinage; Affects; Slavery; Family; Miscegenation.

\footnotetext{
${ }^{1}$ Doutorando em História pela Universidade Federal de Ouro Preto - UFOP. Coordenador Pedagógico e Professor de História na Rede de Ensino Gênesis. E-mail: igor366santos@gmail.com
} 


\section{Introdução}

Atualmente, acredita-se que poucas seriam aquelas pessoas que, perguntadas a respeito, ainda duvidariam de que "Chicas da Silva foram muitas" e que às mulheres coube o papel de submissas tão somente na sociedade brasileira colonial. A história dessa conhecida negra que se uniu ao contratador dos diamantes João Fernandes de Oliveira e que, amancebados, viveram na região do Arraial do Tejuco, comarca do Serro Frio, no século XVIII, foi desmistificada pelos estudos da historiadora Júnia Ferreira Furtado (2003) e contribuiu, significativamente, para uma revisão dos papeis desempenhados pelas mulheres negras e mestiças nas Minas Gerais setecentistas.

A ex-escrava Chica da Silva, tornada forra por João Fernandes de Oliveira no ano de 1753 , teve com ele treze filhos e viveu uma relação duradoura por quinze anos, o que lhe possibilitou vivenciar princípios de ascensão social em meio a uma sociedade escravista, altamente hierarquizada e com práticas de Antigo Regime. Chica da Silva, em sua relação com o português, ajudou a demonstrar que, ainda no mundo colonial, a prática do concubinato poderia se constituir numa forma de arranjo familiar que explicitaria a vontade e a escolha dos próprios contraentes por um tipo de relação considerado, pelas autoridades da época, "crimes contra os costumes". E, além disso, evidenciou como as relações conjugais circunscritas no campo das desigualdades, tanto das "qualidades" quanto das "condições", ajudaram a conformar o mestiço universo das Minas Gerais e da América portuguesa em última instância.

As pesquisas que tiveram como principal objetivo retirar as mulheres negras e mestiças de trás das cortinas e as levarem para o palco principal - tornando-as agentes construtoras das complexas dinâmicas e tramas do cotidiano - foram (e ainda são) muitas, e todas nos trazem, de alguma forma, evidências acerca da atuação direta e indireta dessas mulheres na construção do espaço e das culturas que transitaram $^{2}$ na América portuguesa $^{3}$. Evidentemente as suas incontáveis formas de pensar e agir ajudaram a inverter os lugares sociais estabelecidos a priori entre homens e mulheres de "qualidades" e "condições" distintas na colônia portuguesa e, conforme será visto a seguir, o concubinato ajudou neste complexo processo que resultou, não há dúvidas, em estratégias

\footnotetext{
${ }^{2}$ Para uma maior compreensão acerca da noção de "trânsito de culturas", ver em PAIVA, 2008.

${ }^{3}$ Ver, dentre outros, FIGUEIREDO, 1999; MOTT, 1993; PRIORE, 2009; REIS, 2010.
} 
de resistências, numa pluralidade da concepção de família, em relações explicitamente carregadas por confianças e afetividades recíprocas e, ainda, no intrincado processo das mestiçagens na sociedade colonial.

\section{"Viver de portas adentro" para adentrar no mundo das libertas}

No dia 16 de fevereiro de 1734, na freguesia de Nossa Senhora da Boa Viagem de Curral Del Rei, Comarca de Sabará, Manoel Ferreira Villa Nova, natural da freguesia Santiago de Catão, aceitava a admoestação e prometia ao visitador D. Lourenço Jose de Gueiros Coimbra emenda para uma denúncia de suspeita de concubinato. A denúncia foi feita por um xará, Manoel da Silva Vilas Boas, que levou aos conhecimentos do tribunal eclesiástico o fato de Manoel Villa Nova ser casado no Reino e manter-se amancebado na colônia com a preta forra de nome Potencianna ${ }^{4}$.

Sabemos que a privacidade e a intimidade na época da colônia eram precárias. Frestas dos muros, rachaduras das portas e meias paredes - dentre outros fatores que demonstravam a pobreza na América portuguesa e viabilizavam a percepção da vida alheia - eram uma constante na vida de nossos antepassados que buscavam, de todas as formas, "sobreviver na colônia", como se dizia na época ${ }^{5}$. Assim, é fácil imaginar que, por diversas causas, homens e mulheres de todos os tipos e detentores de informações variadas, procuravam as autoridades eclesiásticas para delatarem seus vizinhos, com quem porventura poderiam nutrir alguma desavença ou mesmo apenas por não compactuar com seus pensamentos ou práticas. Em outras palavras, atuavam, como bem lembrou Marco Antonio Silveira (1997, p. 140), como sendo "as bocas do mundo, que tendiam a controlar e avaliar os comportamentos, limitando os espaços para a vivência da individualidade $[\ldots]$ ".

Não sabemos exatamente qual fora a condicionante responsável por ter feito com que Manoel Vilas Boas denunciasse o seu xará. Mas, seja qual foi, ele o fizera com outros também, pois eis que Vilas Boas surge denunciando, além de Villa Nova, outro português, João Dantas Pinto. E para atribuir veracidade e credibilidade à sua delação, dissera que isso o sabia, pois "ouvira dizer"6.

\footnotetext{
${ }^{4}$ AEAM, Devassas, dezembro-setembro de 1733-1734, f. 32.

${ }_{5}^{5}$ Sobre a noção de privacidade e intimidade na época colonial, ver a obra "Histórias íntimas: sexualidade e erotismo na história do Brasil”, de autoria de Mary Del Priore (2011). E, a respeito da pobreza, consultar a obra "Desclassificados do ouro: a pobreza mineira no século XVIII”, de Laura de Mello e Souza (2004). ${ }^{6}$ AEAM, Devassas, idem, f. 44.
} 
Apesar de Vilas Boas, como fizeram outros tantos delatores, justificar a sua denúncia utilizando o argumento pelo que "ouvira dizer", isto é, dando a entender que o caso de mancebia vivenciado por Manoel Ferreira Villa Nova e Potencianna constituíase numa relação em que havia tanto "escândalo" quanto "fama pública", outro ponto merece destaque, a saber, a relação concubinária estabelecida entre pessoas de "qualidades" branca, preta, crioula, cabra, parda, mulata, mameluca e mestiça e de “condições" livre, liberto e escravo.

Aqui, vale destacar, as "qualidades" são entendidas como traços diversos que serviam para caracterizar e qualificar os indivíduos. Poderiam, nesse sentido, se expressar a partir da mobilidade social e econômica do sujeito ou a partir de seu lugar de origem, ascendência familiar, características fenotípicas, dentre outras possibilidades que, em última instância, serviam para hierarquizar as gentes da colônia. Quanto às "condições", tratava-se dos aspectos sócio jurídicos dos homens e mulheres da colônia. Em nossas pesquisas trabalhamos com três condições que intensificaram o trânsito de culturas nas Minas colonial, os "escravos", os "forros" e os "livres".7

Para o período entre os anos 1727-1756, Rangel Cerceau Netto, em sua obra “Um em casa de outro", constatou, por meio das devassas eclesiásticas, que o concubinato acontecia, principalmente, entre indivíduos de condições sócio jurídicas distintas. Esse fato nos permite tecer alguns comentários que possibilitam uma compreensão mais sólida acerca de alguns aspectos do universo colonial e de seus arranjos sociais, a saber, o concubinato enquanto estratégia escravista e como uma opção pelo estado conjugal. Há estudos recentes que versam acerca deste segundo tipo ${ }^{8}$. Por ora, discorreremos apenas acerca do primeiro.

É lugar comum na produção historiográfica mais recente o fato das uniões mistas (legitimadas ou não perante a Igreja) terem atuado como estratégias que foram utilizadas com o intuito de se angariar a ascensão social e, não raro, econômica. E isso ocorreu, sobretudo, com mulheres ${ }^{9}$. No entanto, as maneiras pelas quais entendemos essa constatação não são das mais simples. Pensá-las apenas enquanto "uma dupla exploração de cunho sexual e racial", como propusera certa feita, Júnia Ferreira Furtado (2001, p. 85), tendo como referência Kathleen Higgins (1999), pode resultar em reducionismos

\footnotetext{
${ }^{7}$ Para uma melhor compreensão acerca do sentido da palavra "qualidades", ver o estudo recente de Eduardo França Paiva. Cf. PAIVA, 2015.

${ }^{8}$ Ver, dentre outros, em SANTOS, 2018.

${ }^{9}$ Ver, dentre outros, em FARIA, 1998, 2004; PAIVA, 2001, 2009.
} 
perigosos e em limitações cujos efeitos maiores sejam certo impedimento na compreensão das relações vivenciadas no interior de uma sociedade escravista e que estava em constante movimento.

Não invalidamos a assertiva de Furtado, porém propomos que não se deve esquecer o fato de que a América portuguesa, enquanto uma sociedade que funcionava envolta nos tentáculos do sistema escravista e com princípios definidores das práticas do Antigo Regime tinha, na hierarquização dos indivíduos, um dos seus principais esteios. E que a luta de milhares de mulheres negras e mestiças em prol de sua ascensão social e econômica adquiriu formas variadas que incluíam, até mesmo, as uniões concubinárias. Em outras palavras, propomos que para muitas mulheres, o amancebamento não fora somente o resultado de uma "dupla exploração de cunho sexual e racial”, mas, sim, uma opção visando os seus intentos que, em última instância, desejavam romper ou inverter as rígidas estruturas verticalizantes da sociedade da época. Haja vista os diversos casos que demonstravam o poder e a capacidade de atuação das mulheres no mundo colonial ${ }^{10}$.

Os arquivos de Minas Gerais guardam incontáveis testamentos e inventários post-mortem, além das próprias devassas, que nos permitem contemplar os inúmeros casos de senhores que, ao morrerem ou verem seu fim se aproximando, deixavam suas escravas concubinas e/ou seus filhos frutos dessa relação, alforriados, coartados ou como testamenteiros, dentre outras possibilidades que confirmam uma união na qual houvera existido um princípio de confiança construída mediante acordos e disputas que possibilitavam mobilidades e minimizavam conflitos do cotidiano ${ }^{11}$. As estratégias de ambas as partes ${ }^{12}$ construíram ambivalências que fomentaram diversas possibilidades no mundo escravista colonial invertendo, até mesmo, as hierarquias rígidas nas quais a sociedade tentava se sustentar.

O que a produção mais recente vem argumentando é que essas práticas desempenhadas por diversos senhores foram possíveis por meio da atuação individual e/ou coletiva de muitas escravas. Mais estrategicamente pensadas ou não, de uma forma

\footnotetext{
${ }^{10}$ Esse protagonismo assumido pelas mulheres no universo colonial está relacionado, dentre outros fatores, à noção da matrifocalidade visto no grupo das africanas e suas descendentes e, aqui na colônia, reproduzida e/ou redirecionada/redimensionada. Sobre isso ver, dentre outros, em CERCEAU NETTO, 2013; FARIA, 2004, PRAXEDES, 2008; PAIVA, 2001, FIGUEIREDO, 1999.

${ }^{11}$ Sobre este aspecto, ver, dentre outros, em PEREIRA, 2009; LOPES, 1998.

${ }^{12}$ Há uma vasta historiografia que debate as formas de resistência no período colonial e imperial. A produção é vasta e surgiu no esteio do revisionismo historiográfico dos anos 1980/1990. Sobre isso, ver, dentre outros, em PAIVA, 2000, 2001 e 2009; SCHWARTZ, 1998; LARA, 1988; CHALHOUB, 1990; REIS e SILVA, 1989; FARIA, 1998.
} 
ou de outra, resultaram de ações das próprias mulheres cativas ${ }^{13}$ que buscavam os seus espaços e não da benevolência de seus proprietários, por mais que, em alguns casos, essa hipótese possa ser aventada ${ }^{14}$.

O caso da forra Antônia parece ser um bom exemplo de como a união com um homem branco poderia render (como de fato rendera) às mulheres escravas benesses e encurtar os seus caminhos rumo ao intento primário da maioria dos cativos: a sua liberdade. Conforme destacou Kátia Mattoso (2003, pp. 174-175), “Graças ao seu jeito de saber viver, o escravo empenha-se em apressar a passagem que leva do passado mítico, perdido, através do presente difícil, a um futuro de liberdade idealizada”. Ex-escrava do português sargento-mor Francisco Xavier da Costa, Antônia conseguira a sua manumissão devido à boa relação estabelecida com o seu senhor e esse, como forma de reconhecimento e de outros aspectos por ele não mencionados mas que, sabemos, estiveram presentes nas relações estabelecidas entre senhores e escravos, a alforriava, juntamente com sua filha, no ato de registro do seu testamento.

Francisco Xavier, natural de Lisboa e morador de Sabará, em 1749, ano em que fizera o seu testamento, destacava: “[...] possuo uma escrava por nome Antônia que pelos bons serviços deixo forra e livre e isenta de cativeiro a qual tem uma filha por nome Anna a quem passei carta de alforria e novamente a declaro forra $[\ldots]]^{\prime 15}$.

$\mathrm{Na}$ sociedade colonial libertar-se do cativeiro constituíra intento primário dos cativos, como já dito e, para alcançar a sua liberdade, inúmeros cativos lançaram mão de estratégias de naturezas distintas. Uma vez alcançada a liberdade, um pré-requisito indispensável para ascender-se no universo das diferenças e desigualdades, o esforço de manter-se forro era cotidiano, uma vez que a reescravização era algo possível e praticado com relativa constância. E isso, do lado do senhor, era também verdadeiro, pois, como se pode notar, a ênfase na reiteração, por parte de Francisco Xavier, na alforria concedida à Anna, filha de Antônia, é notória. Por essa razão, é plausível que vejamos esse feito como o desejo latente do senhor em conceder alforria à prole de sua cativa. Sobre esse fato,

\footnotetext{
13 Alguns dos trabalhos mais recentes que evidenciam o protagonismo das mulheres enquanto agentes responsáveis por suas próprias histórias e conquistas são XAVIER; FARIAS e GOMES (Orgs.), 2012; REIS, 2010; CERCEAU NETTO, 2013.

${ }^{14}$ Ver, dentre outros, em PAIVA, 2001 e 2009; FARIA, 2004; GONÇALVES, 2011.

15 APM/CMS - códice 20, f. 36. Testamento de Francisco Xavier da Costa - Sabará 12 de junho de 1749. Esse documento também fora utilizado por Eduardo França Paiva (2009, p. 124), porém o autor o contemplara noutro aspecto. Discorrera acerca do zelo que Francisco Xavier alimentara para com a mulatinha Anna, filha de Antônia.
} 
algumas hipóteses poderiam ser aventadas, fosse, aqui, o nosso objetivo, tais como: a alforria como concessão pelos bons serviços prestados por Antônia; a alforria enquanto reconhecimento de uma filha fruto de relação concubinária com sua cativa, dentre outras possibilidades sobre as quais não abordaremos neste artigo, mas que, certamente, merecem a atenção por parte dos historiadores, pois explicita a complexidade do mundo dos afetos e das intrincadas relações de poder que envolviam os senhores e suas escravas.

Contudo, a situação aqui que nos interessa é que a ex escrava Antônia conseguira alforriar-se, bem como à sua filha Anna, e expressa a busca pela mobilidade tão almejada e possível no mundo colonial. Não foram raros os casos como esse. Libertar-se, e também à sua prole, estava na ordem do dia de milhares de mulheres que habitaram a América portuguesa e que, mesmo lançando mão de inúmeras estratégias de resistência e sobrevivência, não escaparam das agruras do sistema escravista. Andréa Lisly Gonçalves (2011) ressaltou que as práticas de alforria, antes de qualquer coisa, constituíam-se em relações de poder marcadas por estratégias de senhores e cativos em busca de seus interesses.

Cientes de todas as dificuldades em que viviam diversas cativas e coartadas, em muitos casos, optaram pelo concubinato como forma de liberdade para seu corpo e o de seus rebentos. Conforme afirmou Eliane Cristina Lopes (1998, p. 123): “amancebar-se com seu dono aparecia como uma das poucas formas de deixar a seus filhos uma condição melhor de vida".

Antônia, nesse caso, pode representar apenas mais uma "gota" dentro de um "oceano" de possibilidades vivenciadas por inúmeras outras escravas que conseguiram suas alforrias graças à boa convivência e certos tratos para com seus senhores. Os bons serviços prestados por elas a eles e a seus familiares não eram atitudes despretensiosas por parte destas mulheres, afinal, possibilitaram muitos ganhos e auxílios e as inscreveram como protagonistas de suas histórias. Em função das estratégias envolvendo as relações sexuais e familiares o número de alforrias no universo feminino fora superior ao dos homens em muitas regiões e suas razões podem ser encontradas nas tramas do próprio cotidiano $^{16}$.

É importante pontuar que não apenas as relações familiares e sexuais marcavam essas estratégias de mobilidades, mas também o domínio dessas mulheres no comércio e nos serviços domésticos, em que as aproximações com seus senhores eram maiores e a

${ }^{16}$ Ver, dentre outros, em MATTOSO, 2003; PAIVA, 2001, 2009. 
inversão de papeis, não raro, efetivava-se ${ }^{17}$. Vale lembrar também que a lógica e a dinâmica colonial eram demasiadamente complexas e que análises reducionistas que contemplam as mulheres negras e mestiças como vítimas exploradas tão somente não se sustentam mais, tendo em vista que, hoje, já se reconhece que "ao lado da sempre presente violência, havia um espaço social que se tecia tanto de barganhas quanto de conflitos", como bem lembraram João José Reis e Eduardo Silva em sua obra "Negociação e conflito" (1989, p. 7).

Outro caso em que é possível perceber a concessão de alforria em função da boa relação estabelecida entre um senhor e sua escrava está registrado no testamento do português Balthazar Marques de Oliveira, natural do Bispado do Porto.

Assim registrava o testador:

Declaro que a minha escrava Maria pelo bem que me tem servido quero que depois da minha morte fique forra e livre, e por ter adquirido com a sua agência as duas negras Luzia e Joanna lhe hei por bem dar para que seja propriamente suas, pois demito de mim todo o poder e domínio que nelas possa ter côn tanto que este se intenda depois de minha morte ${ }^{18}$.

Como Francisco Xavier, Balthazar Marques também fizera questão de registrar que a causa da manumissão que concedia à Maria devia-se aos bons serviços por ela prestados. Porém, outro aspecto relevante para a compreensão das relações familiares vivenciadas entre alguns senhores e suas escravas, e onde o concubinato e o casamento podem ter atuado como facilitadores e mediadores dos intercursos em prol da liberdade, é a menção que o próprio testador faz à agência de sua escrava.

Destacando que Maria teria "adquirido com a sua agência as duas negras Luzia e Joanna", o testador possibilita a seguinte inferência: a estratégia de conquista da escrava para com o seu senhor fora tão convincente que ele lhe concedia espaços para que ela pudesse trabalhar e angariar seus próprios bens, o que incluía escravos. Ao cabo desta empreitada, tendo já conquistado o seu senhor, Maria conquistara também, mesmo que de forma pré-datada, a sua alforria. Percebe-se, seguindo essa linha interpretativa, que as práticas de amasiamentos favoreceram, a algumas, o fim a que a grande maioria das cativas almejava: a sua liberdade. Igualmente, casos como esses deram a essas mulheres

\footnotetext{
${ }^{17}$ Ver, dentre outros, em FARIA, 2004; PAIVA, 2001; PANTOJA, 2001; FIGUEIREDO, 1999.

${ }^{18}$ IBRAM/MO-CBG/CPO-LT 01 (1) 230-235. Testamento de Balthazar Marques de Oliveira 06/08/1722.
} 
possibilidades de adquirirem bens materiais, transitarem no mundo dos libertos e legarem aos seus filhos o mundo dos livres.

Entretanto, para além da realização do objetivo prático da alforria, essas relações concubinárias vivenciadas pelos senhores e suas cativas, não impediram a existência de laços verdadeiramente afetivos entre os senhores e as suas escravas ${ }^{19}$. Pelo contrário, tanto essas possibilidades foram efetivadas no cotidiano quanto contribuíram para a existência das famílias mestiças nas Minas setecentistas. Essas famílias mestiças, dentro desse contexto, podem ser compreendidas enquanto laços conjugais construídos por homens e mulheres de "qualidades" e "condições" diferentes. E mais, por se tratar de relações de amasiamento, esses enlaces estavam situados no campo da ilegitimidade, o que lhes garante o espaço das resistências.

Dito de outra forma, o que buscamos explicitar é que o fato de muitas mulheres negras e mestiças terem lançado mão do amasiamento com fins estratégicos para a sua liberdade e a de seus rebentos, não significou que tais uniões não pudessem culminar em formações de famílias com sinceridade, afetividade, estabilidade e duração. Quanto aos senhores essa assertiva também é verificável, pois o usufruto dos corpos de suas propriedades os levaram à reincidência nos tribunais e os fizeram preterir suas esposas em amor às suas concubinas em alguns casos. Isso ocorrera com o português Francisco da Rocha dos Santos.

Homem casado, que vivia amancebado com sua escrava de nome Ursula, com quem inclusive tivera vários filhos, Francisco preferira sua concubina em detrimento de sua verdadeira esposa, pois a essa dava "muito má vida" e a maltratava como se escrava fosse. Em contrapartida, a sua escrava era tratada com distinção e zelo, "como Senhora, governando esta casa $[\ldots]^{\prime 20}$.

Casos como o do português Francisco foram responsáveis por diversos maus tratos vivenciados por muitas esposas na América portuguesa. Numa época e sociedade em que, quando muito, as sinhás brancas poderiam chegar às varandas de suas casas, a submissão feminina era justificada por meio da moral cristã e tentava-se, a todo custo, moldar as mulheres a partir da imagem da santa imaculada. Posto isso, não foram poucas

\footnotetext{
${ }^{19}$ Sobre isso, ver, dentre outros, em ÂNGELO, 2013.

${ }^{20}$ AEAM, Devassas, Liv. Testemunhas, jun.- abr. de 1748-1749, f. 63.
} 
as vítimas feitas pela misoginia reinante ${ }^{21}$. Mas, igualmente, não foram poucos os casos surgidos como respostas a essa mesma realidade.

Outro português, esse de nome Manoel Francisco Monte Negro, também deixava transparecer um sentimento de afeto por ele alimentado à sua escrava, de "qualidade" cabra e de nome Apolônia. Não constando ser homem casado, apenas sabia-se, na própria vizinhança, que ele nutria um sentimento de carinho por Apolônia. Consta que ambos andavam juntos há muitos anos e que Manoel Francisco a tinha de forma muito afetuosa e "por cujo amor desta" permanecia "ali curvado"22.

O caso de Manoel e Apolônia nos permite constatar que ambos optaram pelo concubinato como forma de união familiar e como espaço dentro do qual puderam viver o amor recíproco, haja vista que o documento deixa transparecer que Manoel não abandonava Apolônia por sê-la sua amante. Além disso, igualmente reforça a longa duração deste relacionamento, o que inviabiliza ou, no mínimo, enfraquece argumentos que buscam atrelar relações desse tipo à marginalidade, promiscuidade, instabilidade, dentre outros fatores que reduzem a capacidade de ação dos envolvidos.

Uniões mistas como essas podem revelar que o concubinato representou uma opção entre as partes visando atender interesses distintos e também atuou como possibilidade para se viver formas sinceras de afetividades. Nesse sentido é forçoso reconhecer que essas uniões foram, para muitos casais - e apesar de inúmeros empecilhos -, maneiras encontradas para se viver relacionamentos amorosos. Como advertira Cerceau Netto (2017, p. 115) “esse tipo de relação, durante o século XVIII, causava escândalo aos religiosos, mas era um tipo de relacionamento que servia aos interesses de mulheres e homens".

Como já citado, não se deve esquecer que tais envolvimentos afetivos deram-se no seio de uma sociedade escravista e que no anseio de muitas cativas que recorriam às práticas do amancebamento estava, em primeira instância, o sonho e a luta por sua liberdade. Por isso, muitas optaram pelo "viver de portas adentro" com seus senhores para que pudessem entrar no mundo das libertas.

Alforriar-se, entretanto, por mais esperado que fosse por estas mulheres (e pelos escravos, de modo geral), bem como por melhor que pudesse parecer, não era garantia de que elas fossem conseguir levar uma vida tranquila diante das mazelas sociais infligidas

\footnotetext{
${ }^{21}$ Sobre a moral a qual as mulheres no período colonial se apresentaram como reféns, ver, dentre outros, em PRIORE, 2009, 2011, 2013; ALGRANTI, 1993 e LOPES, 1998.

${ }^{22}$ AEAM, Devassas, Liv. Testemunhas, jun.-abr. de 1748-1749, f. 77.
} 
por sua antiga "condição". Pelo contrário, muitas, uma vez libertadas, vagavam pelos becos e vielas destas Minas Gerais correndo riscos que iam desde a possibilidade de reescravização até as dificuldades enfrentadas devido aos estigmas que lhes eram imputados para toda a sua vida. Nesse contexto, muitas ajudaram a engrossar o caldo da pobreza $^{23}$. A luta pós-cativeiro apenas mudava de rumo. Se antes se lutava pela liberdade, ao consegui-la passava-se à luta pela distinção. Nesse processo buscava-se a conquista de bens materiais, dentre eles cativos, uma segunda prática comum dos ex escravos que conseguiam ascender-se social e economicamente. ${ }^{24}$

É possível que na colônia o ritmo das informações tenha circulado de forma acelerada, especialmente em regiões urbanizadas como foi o caso de Minas Gerais ${ }^{25}$. Por essa razão não é de se espantar que as pessoas estivessem sempre a par do que se passava na vida de seus conhecidos ou de outras experiências vividas por algum desconhecido, em regiões próximas ou distanciadas geograficamente, e que buscassem maneiras alternativas que lhes proporcionassem a superação de seus obstáculos. O fato é que se procurarmos a todo instante ressaltar o nosso vínculo com uma historiografia que defende a existência de um intenso trânsito de culturas $^{26}$ na América portuguesa, não podemos nos esquecer de que esse só foi possível devido ao movimento, naturalmente precedente, que era a complexa circulação e misturas entre pessoas de "qualidades" e "condições" distintas. Como consequência esse fato ajudou no sentido de conectar mundos, em essência, díspares ${ }^{27}$.

Pensando nisso, muitas mulheres, além de almejarem as suas alforrias por meio das estratégias familiares, utilizaram-nas, de igual maneira, para adquirirem bens materiais que lhes dessem mínimas condições de sobrevivência fora do cativeiro.

Outra possibilidade interpretativa seria a de que as uniões estáveis poderiam resultar na efetivação do matrimônio, o que levava a um reconhecimento social naquela sociedade. O casamento, muitas vezes, foi tratado como estratégia para evitar que o testador tivesse que reconhecer seus filhos ilegítimos ou naturais que pudessem tomar parte do seu pecúlio e evitar a árdua empreitada cotidiana de buscar os direitos a partir da

\footnotetext{
${ }^{23} \mathrm{Um}$ dos estudos considerados clássicos nesse assunto, e um dos que abriram as discussões da pobreza ao estilo de uma discussão situada no campo de uma história social revisitada, ainda na década de 1980, fora a já mencionada obra "Desclassificados do ouro", de Laura de Mello e Souza (2004).

${ }^{24}$ Diversas formas de estratégias utilizadas por mulheres negras e mestiças, escravas ou forras, na sociedade colonial podem ser vislumbradas no estudo de Luciano Figueiredo. Cf. FIGUEIREDO, 1999.

${ }^{25}$ Cf. PAIVA, 2001; 2009; 2012.

${ }^{26}$ Sobre a noção de "trânsito de culturas", ver em PAIVA, 2008.

${ }^{27}$ Cf. GRUZINSKI, 2001. Vale, aqui, igualmente, mencionar que Serge Gruzinski já nos advertia que, no fundo, todas as sociedades, de alguma forma, são mestiças.
} 
ilegitimidade. Todavia, é comum observar que muitos testadores utilizavam-se de outras estratégias para legar a seus filhos ilegítimos seus bens e, na falta desses, instituíam sua concubina como herdeira. Daí a importância das boas relações construídas no cotidiano entre os senhores e suas escravas que, não raro, poderiam terminar como suas amásias.

Pode-se dizer, portanto, que a América portuguesa, a partir de suas características definidoras, constituiu-se num palco de encenações múltiplas cuja finalidade, em última instância, era o "sobreviver em colônia" criando espaços para atuações diversas. Nesse sentido, concordamos com Eduardo França Paiva (2001, p. 79) quando ele afirma que "valia a pena então forjar situações e afetos, regá-los e, ainda que muitos anos depois, colher o fruto de tão complexo investimento".

As uniões mistas foram estratégias utilizadas por milhares de mulheres que almejavam a inversão da máxima senhor/escravo sob a forma de tensão e, atualmente, são fatos constatados e constatáveis em meio à multifacetada sociedade colonial. É verdade, também, que essas mesmas uniões foram favorecidas pelas próprias dinâmicas construídas e vivenciadas no dia a dia por homens e mulheres de todas as "qualidades", "condições", credos, naturalidades, dentre outros aspectos que auxiliaram nas conformações dos costumes presentes nas Minas setecentistas. Assim, essas mesmas uniões na forma de amasiamentos revestiram-se do manto sob o qual é possível compreender as constantes necessidades de adaptações, acomodações, mas também de rejeições e impermeabilidades em uma sociedade que se embriagava, simultaneamente, de valores culturais e de referências distintas, que abarcavam o universo cultural de europeus, indígenas, africanos e dos próprios mestiços.

Para além das atitudes proativas das mulheres que lançavam mão de relações afetivas com seus senhores, essas estratégias também figuraram no intrincado universo escravista dando possibilidades de conquistas de mobilidades econômicas e sociais. Seguindo essa visão, percebe-se que o modelo de família situado fora do campo de legitimidade cristã exercia papel fulcral entre as práticas consuetudinárias e atuou como responsável direto pela ampliação da noção de família ${ }^{28}$ no período colonial.

Muitos foram os casos em que homens e mulheres viveram juntos por muitos anos. Permanecendo unidos, tiveram filhos e construíram relações duradouras que, apesar

\footnotetext{
${ }^{28}$ Em estudo recente, foi proposto a noção de "Famílias Plurais" para se pensar e entender algumas lógicas constitutivas que envolviam os arranjos familiares na América portuguesa. Noção que, a partir da qual, se situavam possibilidades diversas de experiências conjugais que se constituíam enquanto resultados e resultantes das complexas dinâmicas internas da colônia, inclusive no tocante às mestiçagens. Ver a obra "Familias Plurais" (SANTOS, 2018).
} 
de não terem sido celebradas "em face da Igreja", constituíram-se enquanto possibilidades reais para aqueles que assim o desejaram. Sem nos esquecermos de que as práticas amorosas se circunscreveram a partir de objetivos diversificados que envolveram interesses díspares entre pessoas de "qualidades" e "condições" diferentes foram frutos, em última instância, dos processos de mestiçagens que, paralelamente, também ajudaram a forjar a sociedade colonial. Seguindo esse caminho de interpretação, é possível perceber que as uniões estáveis foram mais uma prática consuetudinária e legitimada nesse universo dos costumes, do que apenas "remédio para as dificuldades de casar" de acordo com a Igreja, como destacara, certa vez, Luiz Carlos Villalta (1993, p. 52).

Desse modo, há de se matizar inúmeros estudos que afirmaram, por exemplo, ser o concubinato fruto das dificuldades encontradas pelos portugueses para se casar. Resultados que relacionam tão somente as práticas do amasiamento à discrepância demográfica, constituída a partir da predominância de mulheres negras e mestiças sobre as brancas ou ainda ao resultado da desclassificação social, também precisam ser relativizados. Outras abordagens que, nos últimos anos, associaram as uniões não sacramentadas pela Igreja às formas marginais de relacionamentos amorosos devem ser, igualmente, melhor explicadas e contextualizadas ${ }^{29}$. Sendo assim, entende-se que as práticas concubinárias constituíram-se enquanto produto final e princípio constituinte das mestiçagens processadas na América portuguesa. Logo, sua compreensão também poder ser buscada no estudo dos costumes daquela sociedade.

Em um ambiente onde ocorreram misturas "entre seres humanos, imaginários e formas de vida vindos de quatro continentes - América, Europa, África e Ásia" (GRUZINSKI, 2001, p. 62), deve-se considerar que os costumes também se diversificaram e atuaram, não necessariamente, à margem das normas, mas, pari passu às mesmas. Vanda Lúcia Praxedes (2003, p. 117) já nos advertia dizendo que "existia uma tensão entre o proposto na lei e a mobilidade da própria vida e dos relacionamentos".

Se considerarmos as uniões mistas enquanto estratégias escravistas de resistência tão somente, muito provavelmente concordaremos com a autora. Todavia, trazendo-as para o campo das possibilidades encontradas pelos indivíduos que deram cor e forma à sociedade mineira nos setecentos, e reconhecendo essas dinâmicas como o resultado das práticas de mestiçagens aqui processadas, tendemos a relativizar a argumentação de Praxedes. Para complementá-la pontua-se que a conjugalidade das

${ }^{29}$ Dentro deste campo de possibilidades, ver, dentre outros, em FIGUEIREDO, 1997, 1999; VAINFAS, 1989; SOUZA, 2004; SILVA, 1984, LONDOÑO, 1999, VILLALTA, 1993; RAMOS, 1973. 
pessoas que viviam de "portas adentro" ou "como se casadas fossem" conformavam-se enquanto complementaridades ao modelo tridentino de matrimônio. Isso significa dizer que, para além das tensões entre as leis e as mobilidades cotidianas, tais práticas atuavam onde as pessoas encontravam maneiras de mediações culturais ${ }^{30}$ que possibilitavam a coexistência das leis e dos costumes.

Para o padre jesuíta Raphael Bluteau (1712, p. 133), os costumes podem ser entendidos na forma de hábitos ou modos particulares de se viver, próprios de qualquer nação, cidade ou lugar e são até mesmo mais fortes e poderosos do que a leis, ordens e estatutos humanos. Em última instância, o que ocorre em relação aos costumes e o porquê de termos proposto o adendo quanto à argumentação de Praxedes, é que uma determinada prática, compreendida enquanto benéfica dentro de certa comunidade e sendo ali reproduzida, adquire força de lei. Por essa razão são comuns as alterações no chamado direito positivo mediante as mudanças prévias sofridas no consuetudinário.

Acredita-se que as uniões mistas, legitimadas ou não perante a Igreja, constituíram práticas complementares de relações familiares numa América portuguesa profundamente mestiçada. Pode-se perceber por meio desses relacionamentos a valorização da família tanto como almejara e defendera o clero quanto como práticas dos costumes forjados nas Minas dos setecentos. Partindo desse pressuposto é plausível reconhecer que a moral cristã também fora determinante para a ampliação da noção de família pluralizando seus sentidos. Isto é, as famílias plurais, se compreendidas dentro de suas especificidades e contextos, podem se apresentar enquanto consequências da política religiosa e das práticas culturais de diferentes grupos sociais processadas pelas mestiçagens e foram frutos, de igual maneira, das tensões existentes entre normas e costumes. Ou seja, constituem, por conseguinte, o resultado estabelecido a partir da conexão entre mundos distintos e seus respectivos valores.

\section{Considerações finais}

Sem pretensões de esgotar o tema, este artigo busca tão somente contribuir com uma historiografia que entende as relações socioculturais da colônia como dinâmicas e complexas. A partir desta lente, considera-se impossível a redução e/ou rotulação dessas

\footnotetext{
${ }^{30}$ Segundo Serge Gruzinski, a noção de "mediação cultural" marca um processo de mão dupla. Ou seja, o mediador, ao mesmo tempo em que impõe o seu referencial cultural também sofre o processo inverso. Cf. GRUZINSKI, 1997.
} 
realidades coloniais aqui narradas, partindo de máximas que impedem a compreensão de um processo histórico marcado por ações e reações que surgiram a partir de intentos múltiplos de sujeitos inseridos num universo constituído por diferentes e desiguais.

$\mathrm{O}$ artigo se propôs, através da documentação (devassas eclesiásticas e testamentos) e temporalidade (século XVIII) analisadas, entender as relações concubinárias como espaços nos quais era possível desenvolver, simultaneamente, princípios de resistência feminina, expressar práticas de afetividades sinceras, (re)significar as noções de família nas Minas setecentistas expandindo-a, portanto, para além da tradicional visão de família cristã legítima e constituída "em face da Igreja" e, para além de tudo isso, (re)estruturar uma sociedade marcadamente mestiça.

Os casos aqui trazidos compõem parte reduzida de uma documentação que é infinitamente maior. Nesse sentido, aqui, por nos circunscrever aos limites de um artigo, optamos por uma abordagem de caráter qualitativo, mas inexoravelmente atrelado e sustentado por um corpus documental constante nos arquivos mineiros, em parte também devidamente referenciado ao final deste texto.

Em uma conjuntura de intensos debates marcados por premissas extremistas e polarizadas, considera-se de grande relevância uma reflexão que busque aumentar as possibilidades interpretativas acerca de pautas que circunscrevem o nosso cotidiano e viabilizam a contínua e árdua insistência pela preservação de princípios democráticos na sociedade do século XXI- a luta contra o racismo, a família, o feminismo, dentre outros. Sendo assim, uma última premissa sustentada no presente artigo remonta aos escritos do historiador Marc Bloch, quando este menciona um provérbio árabe para preconizar que “os homens se parecem mais com sua época do que com seus pais" (2001, p. 60).

\section{Fontes}

\section{Arquivo Eclesiástico da Arquidiocese de Mariana - AEAM}

- Livros de Devassas Eclesiásticas, Termos de Culpa. Identificações: fevereiro de 1727 dezembro de 1753; janeiro - março de 1731; outubro de 1733 - janeiro de 1734; julho de 1737 - setembro de 1738; julho de 1748 - janeiro de 1750; Z-5 agosto de 1752 - fevereiro de 1756; junho de 1734 - outubro de 1734.

- Livro de Devassas, Testemunhas. Identificações: maio de 1730 - abril de 1731; Z-1 maio - dezembro de 1738; Z-4 junho de 1748 - abril de 1749; Z-8 julho de 1756 - fevereiro de 1757; Z-9 julho - setembro de 1759; Z-11 e 12 janeiro de 1767 - maio de 1778; Z-3 
novembro de 1747- fevereiro de 1748; Z-4 fevereiro de 1748- julho de 1748; Z-5 agosto de 1756- março de 1757.

\section{Centro de Documentação e Informação da Cúria Metropolitana de Belo Horizonte} - CEDIC-BH.

- Livros de Devassas Eclesiásticas, Termos de Culpa. Identificações: dezembro de 1733 - setembro de 1734.

\section{Fontes impressas}

BLUTEAU, Raphael Padre. Vocabulário português e latino. Coimbra: Colégio das Artes da Companhia de Jesus, 1712.

CAB - CONSTITUIÇÕES PRIMEIRAS DO ARCEBISPADO DA BAHIA, feitas $e$ ordenadas pelo ilustríssimo, e reverendíssimo senhor d. Sebastião Monteiro da Vide, arcebispo do dito arcebispado, e do conselho de Sua Majestade, propostas e aceitas em o sínodo diocesano, que o dito senhor celebrou em 12 de junho do ano de 1707. 3. ed. São Paulo: Tipografia 2 de Dezembro, 1853. (1. ed., Lisboa, 1719; 2. ed. Coimbra, 1720).

\section{Referências bibliográficas}

ÂNGELO, Fabrício Vinhas Manini. "Pelo muito amor que the tenho": a família, as vivências afetivas e as mestiçagens na comarca do Rio das Velhas (1716-1780). Dissertação (Mestrado em História). Universidade Federal de Minas Gerais. Belo Horizonte, 2013.

BLOCH, Marc. Apologia da história, ou, o ofício de historiador. Trad. Rio de Janeiro: Jorge Zahar, 2001.

CERCEAU NETTO, Rangel. Um em casa de outro: concubinato, família e mestiçagem na comarca do Rio das Velhas (1720-1780). São Paulo: Annablume/Belo Horizonte: PPGH/UFMG, 2008.

. Entre as formas de se pensar e as maneiras de se viver: a família mestiça e a vida familiar em Minas Gerais colonial. São Paulo: Alameda, 2017.

CHALHOUB, Sidney. Visões da liberdade: uma história das últimas décadas da escravidão na corte. São Paulo: Companhia das Letras, 1990. 
FARIA, Sheila de Castro. A colônia em movimento: fortuna e família no cotidiano colonial. Rio de Janeiro: Nova Fronteira, 1998.

.História da Família e Demografia Histórica. In: CARDOSO, Ciro F. S.; VAINFAS, Ronaldo (orgs.). Domínios da História: Ensaios de teoria e metodologia. Rio de Janeiro: Campus, 1997. pp. 241-258.

. Sinhás pretas, damas mercadoras: as pretas minas nas cidades do Rio de Janeiro e São João Del Rey (1700-1850). Tese (Concurso de professor titular). Universidade Federal Fluminense. Niteroi, 2004.

FIGUEIREDO, Luciano Raposo de Almeida. Barrocas famílias: vida familiar em Minas Gerais no século XVIII. São Paulo: Hucitec, 1997.

O avesso da memória: cotidiano e trabalho da mulher em Minas Gerais no século XVIII. 2. ed. Rio de Janeiro: José Olympio, 1999.

FURTADO, Júnia Ferreira. Chica da Silva e o contratador dos diamantes: o outro lado do mito. São Paulo: Companhia das Letras, 2003.

GOLDSCHMIDT, Eliana Rea. Casamentos mistos: liberdade e escravidão em São Paulo colonial. São Paulo: Annablume, 2004.

GONÇALVES, Andréa Lisly. As margens da liberdade: estudo sobre a prática de alforrias em Minas colonial e provincial. Belo Horizonte: Fino Traço, 2011.

GRUZINSKI, Serge. O pensamento mestiço. Trad. Rosa Freira d'Aguiar. São Paulo: Companhia das Letras, 2001.

HIGGINS, Kathleen J. Licentious liberty, in a Brazilian gold-mining region. Pensilvânia: Pennsylvania State University Press, 1999.

LARA, Silvia Hunold. Campos da violência: escravos e senhores na capitania do Rio de Janeiro, 1750-1808. Rio de Janeiro: Paz \& Terra, 1988.

LONDOÑO, Fernando Torres. A outra família: concubinato, igreja e escândalo na colônia. São Paulo: Loyola, 1999.

LOPES, Eliane Cristina. O revelar do pecado: filhos ilegítimos na São Paulo do século XVIII. São Paulo: Annablume; FAPESP, 1998.

LOTT, Miriam Moura. Na forma do ritual romano: casamento e família em Vila Rica (1804-1839). São Paulo: Annablume/Belo Horizonte: PPGH/UFMG, 2008.

MACHADO, Cacilda. A trama das vontades: negros, pardos e brancos na produção da hierarquia social (São José dos Pinhais - PR, passagem do século XVIII para o XIX). Tese (Doutorado em História). Universidade Federal do Rio de Janeiro. Rio de Janeiro, 2006. 
MARCÍLIO, Maria Luiza. Caiçara: terra e população. São Paulo: Paulinas, CEDHAL, 1986.

A cidade de São Paulo: povoamento e população (1750-1850). São Paulo: Pioneira/Edusp, 1973.

Crescimento demográfico e evolução agrária paulista, 1700-1836. Tese (Livre Docência). Universidade de São Paulo. São Paulo, 1974.

MATTOSO, Kátia de Queirós. Ser escravo no Brasil. São Paulo: Brasiliense, 2003.

MAXWELL, Kenneth. A Devassa da Devassa: A Inconfidência Mineira: Brasil Portugal (1750-1808). Trad. Rio de Janeiro: Paz \& Terra, 1978.

MOTT, Luiz. Rosa egipcíaca: uma santa africana no Brasil. Rio de Janeiro: Bertrand Brasil, 1993.

PAIVA, Eduardo França. Escravidão e universo cultural na colônia: Minas Gerais, 1716-1789. Belo Horizonte: Editora UFMG, 2001.

Escravos e libertos nas Minas Gerais do século XVIII: estratégias de resistência através dos testamentos. 3. ed. São Paulo: Annablume; Belo Horizonte: PPGH/UFMG, 2009. (Coleção Olhares).

. Dar nome ao novo: uma história lexical da Ibero-América entre os séculos XVI e XVIII (as dinâmicas de mestiçagens e o mundo do trabalho). Belo Horizonte: Autêntica, 2015.

- Trânsito e mobilidade entre mundos: escravidão globalizada, comércio e práticas culturais. In: FURTADO, Júnia Ferreira (org.). Sons, formas, cores e movimentos na modernidade atlântica: Europa, Américas e África. São Paulo: Annablume/Belo Horizonte: PPGH-UFMG, 2008.

PEREIRA, Maria Luisa de Castro. O sangue, a palavra e a lei: faces da ilegitimidade em Sabará, 1713-1770. Dissertação (Mestrado em História). Universidade Federal de Minas Gerais. Belo Horizonte, 2004.

PRAXEDES, Vanda Lúcia. A teia e a trama da fragilidade humana: os filhos ilegítimos em Minas Gerais, 1770-1840. Dissertação (Mestrado em História). Universidade Federal de Minas Gerais. Belo Horizonte, 2003.

Segurando as pontas e tecendo tramas: mulheres chefes de domicílio em Minas Gerais, 1770-1880. Tese (Doutorado em História). Universidade Federal de Minas Gerais. Belo Horizonte, 2008. 
PRIORE, Mary Del. Ao sul do corpo: condição feminina, maternidade e mentalidade no Brasil Colônia. São Paulo: UNESP, 2009.

Histórias íntimas: sexualidade e erotismo na história do Brasil. São Paulo: Planeta, 2011.

EIS, Adriana Dantas. As mulheres negras por cima, o caso de Luzia Jeje: escravidão, família e mobilidade social - Bahia, c. 1780-c.1830. Tese (Doutorado em História). Universidade Federal Fluminense. Niteroi, 2010.

REIS, João José; SILVA, Eduardo. Negociação e conflito: a resistência negra no Brasil escravista. São Paulo: Companhia das Letras, 1989.

SAMARA, Eni de Mesquita. A família brasileira. 3 ed. São Paulo: Brasiliense, 1986.

. As mulheres, o poder e a família. São Paulo, século XIX. São Paulo: Marco

Zero \& Secretaria de Estado da Cultura de São Paulo, 1989.

SANTOS, Igor. Famílias plurais: uniões mistas e mestiçagens na comarca de Sabará (1720-1800). Curitiba: Appris, 2018.

Longe de suas esposas, mas ainda em família: o concubinato adulterino como condições para as mestiçagens (Sabará, século XVIII). e-Hum Revista Científica do Departamento de Ciências Humanas, Letras e Artes do Uni-BH. Belo Horizonte, vol. $11, n^{\circ} 2.2018$. p. 54-65.

SCHWARTZ, Stuart B. Segredos internos: engenhos e escravos na sociedade colonial, 1550-1835. Trad. São Paulo: Companhia das Letras, 1988.

SCOTT. Ana Silvia Volpi. A família como objeto de estudo para o Historiador. In: ALTHOFF, Coleta Rinaldi; ELSEN, Ingrid; NITSCHKE, Rosane Gonçalves. (org.). Pesquisando a Família: olhares contemporâneos. Florianópolis: Papa-Livro, 2004. pp. 45-54.

As teias que a família tece: uma reflexão sobre o percurso da história da família no Brasil. História: Questões e Debates. 2009.

. Entre a "curva" e o "caso": três décadas de história da família no Brasil. In:

LIBBY, Douglas Cole; MENESES, José Newton Coelho; FURTADO, Júnia Ferreira; FRANK, Zephyr L. (Orgs.). História da família no Brasil (séculos XVIII, XIX e XX): novas análises e perspectivas. Belo Horizonte: Fino Traço, 2015. pp. 21-49.

SILVA, Maria Beatriz Nizza da. Sistema de casamento no Brasil colonial. São Paulo: T. A. Queiroz: Editora da Universidade de São Paulo, 1984.

Donas mineiras do período colonial. São Paulo: Editora UNESP, 2017. 
SILVEIRA, Marco Antonio. O universo do indistinto: Estado e sociedade nas Minas setecentistas (1735-1808). São Paulo: Hucitec, 1997.

SOUZA, Laura de Mello e. Norma e conflito: aspectos da História de Minas no século XVIII. Belo Horizonte: Ed. UFMG, 1999.

Desclassificados do ouro: a pobreza mineira no século XVIII. 4. ed. rev. e amp. Rio de Janeiro: Graal, 2004.

TEIXEIRA, Paulo Eduardo. O outro lado da família brasileira. São Paulo: Editora da Unicamp, 2004.

VIANA, Andréa Lopes. Visitações episcopais: processos de devassa ocorridos no Arraial do Tijuco, Capitania de Minas Gerais, 1750. Dissertação de Mestrado Profissional Interdisciplinar em Ciências Humanas. Universidade Federal dos Vales do Jequitinhonha e Mucuri/Faculdade Interdisciplinar em Humanidades. Diamantina, 2017.

VILLALTA, Luiz Carlos. A “torpeza diversificada dos vícios": celibato, concubinato e casamento no mundo dos letrados de Minas Gerais (1748-1801). Dissertação (Mestrado em História). Universidade de São Paulo. São Paulo, 1993. 